\title{
Atomic force microscopy imaging reveals the formation of ASIC/ENaC cross-clade ion channels
}

\author{
Pia Jeggle a, Ewan St. J. Smith a, Andrew P. Stewart ${ }^{\text {a }}$, Silke Haerteis ${ }^{\text {b }}$, \\ Christoph Korbmacher ${ }^{\text {b }}$, J. Michael Edwardson ${ }^{\text {a, * }}$ \\ a Department of Pharmacology, University of Cambridge, Tennis Court Road, Cambridge CB2 1PD, United Kingdom \\ ${ }^{\mathrm{b}}$ Institut für Zelluläre und Molekulare Physiologie, Friedrich-Alexander-Universität Erlangen-Nürnberg, Waldstrasse 6, 91054 Erlangen, Germany
}

\section{A R T I C L E I N F O}

\section{Article history:}

Received 11 May 2015

Accepted 28 May 2015

Available online 29 May 2015

\section{Keywords:}

Acid-sensing ion channel (ASIC)

Atomic force microscopy

Channel assembly

Epithelial $\mathrm{Na}^{+}$channel (ENaC)

\begin{abstract}
A B S T R A C T
ASIC and $\mathrm{ENaC}$ are co-expressed in various cell types, and there is evidence for a close association between them. Here, we used atomic force microscopy (AFM) to determine whether ASIC1a and ENaC subunits are able to form cross-clade hybrid ion channels. ASIC1a and ENaC could be co-isolated from detergent extracts of tsA 201 cells co-expressing the two subunits. Isolated proteins were incubated with antibodies against ENaC and Fab fragments against ASIC1a. AFM imaging revealed proteins that were decorated by both an antibody and a Fab fragment with an angle of $\sim 120^{\circ}$ between them, indicating the formation of ASIC1a/ENaC heterotrimers.
\end{abstract}

(c) 2015 Elsevier Inc. All rights reserved.

\section{Introduction}

The ENaC/degenerin superfamily of amiloride-sensitive $\mathrm{Na}^{+}$ channels encompasses $>60$ members [1], and includes the acidsensing ion channel (ASIC) and the epithelial $\mathrm{Na}^{+}$channel (ENaC). ASICs are proton-gated cation channels with a trimeric subunit arrangement [2]. They are abundant in the central and peripheral nervous systems, where they are involved in mechanosensation [3], nociception [4], memory and learning [5], as well as neurodegenerative disorders, such as ischemic stroke, epilepsy and Parkinson's disease [6]. They have also been detected in non-neural tissues, such as cancer cells [7], intestinal epithelial cells [8] and smooth muscle cells $[9,10]$. Subunits encoded by the four ASIC genes may form homo- and heterotrimers with distinct acid-activated currents $[11,12]$. ASICs are generally less sensitive to amiloride inhibition than $\mathrm{ENaC}[13]$. The latter is a heterotrimer usually composed of $\alpha, \beta$ and $\gamma$ subunits [14], and is constitutively active [1]. ENaC was initially identified in the kidney collecting duct [1], where it governs the rate of $\mathrm{Na}^{+}$absorption and plays a critical role in the maintenance of body $\mathrm{Na}^{+}$balance. It has since been detected in

Abbreviations: AFM, atomic force microscopy; ASIC, acid-sensing ion channel; $\mathrm{CHO}$, Chinese hamster ovary; ENaC, epithelial sodium channel; FITC, fluorescein isothiocyanate; HA, hemagglutinin; HEK, human embryonic kidney; VSMC, vascular smooth muscle cell.

* Corresponding author.

E-mail address: jme1000@cam.ac.uk (J.M. Edwardson). many other tissues, including colonic and respiratory epithelial cells, sweat and salivary duct cells, taste cells, endothelial cells, vascular smooth muscle, brain and heart [15]. Further, it is now known that $\delta$-ENaC may replace $\alpha$-ENaC in a tissue-dependent and disease-related manner $[16,17]$. Consistent with its expression pattern, dysfunction of ENaC plays a pivotal role in salt-sensitive hypertension, cystic fibrosis and chronic airway disease [18-20].

Based on the sequence homology between ASIC and ENaC, their propensity to form heteromeric channels, and their nearubiquitous expression, the formation of cross-clade channels was proposed. Recent findings, using experimental approaches such as co-immunoprecipitation, Förster resonance energy transfer and total internal reflection microscopy, support the suggestion that channels can be formed through an interaction between $\mathrm{ENaC}$ and ASIC [21-23]. Interestingly, amiloride-sensitive currents, which do not conform to the common $\mathrm{ENaC}$ fingerprint and can be inhibited by the specific ASIC blocker psalmotoxin-1, an antagonist of ASIC1a homomers and ASIC1a/2b heteromers [24], have been detected in Xenopus oocytes exogenously expressing ASIC and ENaC subunits [21], and in glioblastomas, where a direct interaction between $\alpha / \gamma$ ENaC and ASIC1 was observed [22,23,25]. Moreover, this conductance was not present in non-cancerous astrocytes [7]. Although these results are consistent with the formation of cross-clade hybrid channels, structural evidence for the existence of such channels is still lacking. Here, we used atomic force microscopy (AFM) [14] to determine whether ASIC and ENaC subunits are indeed able to form a heteromultimeric ion channel. 


\section{Materials and methods}

\subsection{Constructs}

cDNAs for human WT $\alpha-, \beta$-, and $\gamma$-ENaC, each bearing an $\mathrm{N}-$ terminal hemagglutinin (HA) epitope tag and a C-terminal V5 tag, in the pcDNA3.1 vector have been described previously $[14,16]$. A Cterminal Myc epitope tag was added to a human ASIC1a construct, also in pcDNA3.1.

\subsection{Expression and functional analysis of epitope-tagged ASIC1a}

Chinese hamster ovary (CHO) cells were grown at $37{ }^{\circ} \mathrm{C}$ in Ham's F-12 nutrient mixture (Life Technologies), supplemented with $10 \%$ (v/v) fetal bovine serum (Sigma), $100 \mathrm{U} / \mathrm{ml}$ penicillin, and $100 \mu \mathrm{g} / \mathrm{ml}$ streptomycin, in $5 \%(\mathrm{v} / \mathrm{v}) \mathrm{CO}_{2} /$ air. Cells growing on $35-\mathrm{mm}$ culture dishes coated with $100 \mu \mathrm{g} / \mathrm{ml}$ poly-L-lysine (Sigma) were transfected with a mixture of DNA encoding ASIC1a $(0.9 \mu \mathrm{g})$ and EGFP $(0.09 \mu \mathrm{g})$ using Lipofectamine LTX (Life Technologies). (The EGFP was subsequently used to identify transfected cells).

Whole-cell patch-clamp recordings from $\mathrm{CHO}$ cells were performed at room temperature. The intracellular solution contained (in $\mathrm{mM}$ ): $110 \mathrm{KCl}, 10 \mathrm{NaCl}, 1 \mathrm{MgCl}_{2}, 1$ EGTA, 10 HEPES, $2 \mathrm{Na}_{2} \mathrm{ATP}, 0.5$ $\mathrm{Na}_{2} \mathrm{GTP}$ in MilliQ water; $\mathrm{pH}$ was 7.3, and osmolarity was adjusted to 310-315 mOsm with sucrose. The extracellular solution contained (in mM): $140 \mathrm{NaCl}, 4 \mathrm{KCl}, 2 \mathrm{CaCl}_{2}, 1 \mathrm{MgCl}_{2}, 10$ HEPES, 4 glucose in MilliQ water; osmolarity was adjusted to 300-310 mOsm with sucrose, and $\mathrm{pH}$ was adjusted as required. Patch pipettes were pulled from borosilicate glass capillaries (Hilgenberg) using a Model P-97, Flaming/Brown puller (Sutter Instruments), and had a resistance of 3-6 M $\Omega$. Data were acquired using an EPC10 amplifier (HEKA) and Patchmaster software (HEKA). Whole-cell currents were recorded at $20 \mathrm{kHz}$. Pipette and membrane capacitance were compensated using Patchmaster macros, and series resistance was compensated by $>60 \%$. Currents were evoked using the following

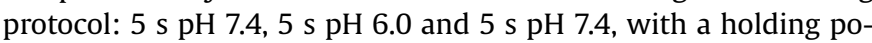
tential of $-60 \mathrm{mV}$.

\subsection{Expression and isolation of epitope-tagged protein from transiently transfected tsA 201 cells}

tsA 201 cells, a transformed human embryonic kidney (HEK) 293 cell line stably expressing an SV40 temperature-sensitive Tantigen, were grown at $37{ }^{\circ} \mathrm{C}$ in Dulbecco's modified Eagle's medium supplemented with $10 \%(\mathrm{v} / \mathrm{v})$ fetal bovine serum, $100 \mathrm{U} /$ $\mathrm{ml}$ penicillin, and $100 \mu \mathrm{g} / \mathrm{ml}$ streptomycin, in $5 \%(\mathrm{v} / \mathrm{v}) \mathrm{CO}_{2} /$ air. Cells were transiently transfected [14], and incubated for $48 \mathrm{~h}$ at $37{ }^{\circ} \mathrm{C}$ to allow protein expression, which was confirmed using immunofluorescence analysis of small-scale cultures. Cells were fixed, permeabilized and incubated with appropriate antibodies. For single transfections, primary antibodies were mouse monoclonal anti-HA (Covance), mouse monoclonal anti-V5 (Life Technologies) and mouse monoclonal anti-Myc (Life Technologies), followed by a fluorescein isothiocyanate- (FITC)-conjugated goat anti-mouse secondary (Sigma). For co-transfections, primary antibodies were rabbit polyclonal anti-HA (Sigma), and mouse monoclonal anti-Myc, and secondary antibodies were FITCconjugated goat anti-rabbit (Sigma) and Cy3-conjugated goat anti-mouse (Sigma). Samples were imaged by confocal laser scanning microscopy.

Protein isolation was carried out as described previously [14], using anti-HA immunoaffinity chromatography to capture the HA epitope tag on the ENaC constructs. Samples were analyzed by SDSPAGE, followed by immunoblotting.

\subsection{AFM imaging}

Isolated proteins were incubated overnight with various combinations of the following antibodies and Fab-fragments: mouse monoclonal anti-V5 (Life Technologies), mouse monoclonal antiFLAG (Sigma), Fab-fragment of mouse monoclonal anti-Myc (Life Technologies), Fab fragment of mouse monoclonal anti-His (Life Technologies). Fab-fragments were freshly generated using the specified antibodies and a Fab Micro Preparation Kit (Thermo Scientific) according to the manufacturer's protocol.

AFM imaging was carried out as described previously [14], using a Bruker Digital Instruments Multimode atomic force microscope controlled by a Nanoscope IIIa controller. Samples were imaged in air (tapping mode), using silicon cantilevers with a drive frequency of $\sim 300 \mathrm{kHz}$ and a specified spring constant of $40 \mathrm{~N} / \mathrm{m}$ (Olympus). The applied imaging force was kept as low as possible $\left(A_{s} / A_{0}\right.$ $\sim 0.85$ ).

\subsection{AFM image analysis}

Particle heights and diameters were measured manually using the Nanoscope V5.31 software and used to calculate molecular volumes according to the equation

$V_{m}=(\pi h / 6)\left(3 r^{2}+h^{2}\right)$

where $h$ is the particle height and $r$ is the radius [26]. This equation assumes that the immobilized particle adopts the form of a spherical cap. The molecular volume of a protein, based on its molecular mass, was calculated using the equation

$V_{c}=\left(M_{0} / N_{0}\right)\left(V_{1}+d V_{2}\right)$

where $M_{0}$ is the molecular mass, $N_{0}$ is Avogadro's number, $V_{1}$ and $V_{2}$ are the partial specific volumes of particle $\left(0.74 \mathrm{~cm}^{3} / \mathrm{g}\right)$ and water $\left(1 \mathrm{~cm}^{3} / \mathrm{g}\right)$, respectively, and $d$ is the extent of protein hydration (taken as $0.4 \mathrm{~g}$ water $/ \mathrm{g}$ protein).

To be accepted as bound antibodies or Fab fragments, peripheral particles needed to have a molecular volume between $150-330 \mathrm{~nm}^{3}$ and $30-115 \mathrm{~nm}^{3}$, respectively. The ranges were applied to minimize confusion between antibodies and Fab fragments, with respective molecular volumes of $\sim 285 \mathrm{~nm}^{3}$ and $\sim 95 \mathrm{~nm}^{3}$. The height of the lowest point between the two particles needed to be greater than $0.3 \mathrm{~nm}$ for the peripheral particle to be considered bound. Additionally, any particle was rejected if its length was greater than twice its width. To be considered a double binding event, all particles and both binding events needed to meet the above criteria.

\subsection{Statistical analysis}

Histograms were drawn with bin widths chosen according to Scott's equation:

Bin width $=3.5 \sigma / n^{1 / 3}$

where $\sigma$ is an estimate of the standard deviation and $n$ is the sample size [27]. When Gaussian curves were fitted to the data, the number of curves was chosen so as to maximize the $r^{2}$ value while giving significantly different means using Welch's t-test for unequal sample sizes and unequal variances [28]. Co-immunoprecipitation efficiency was calculated by densitometric analysis of the immunoblot bands using Image software $(\mathrm{NIH})$, taking dilution factors into consideration. 


\section{Results}

We showed previously that addition of HA and V5 tags onto the $\alpha, \beta$ and $\gamma$ ENaC subunits does not affect either single-channel conductance or ion selectivity, compared with wild type ENaC [14]. To test the activity of the Myc-tagged human ASIC1a construct, it was expressed by transient transfection of $\mathrm{CHO}$ cells, and challenged by exposure to $\mathrm{pH}$ 6.0. A robust, rapidly inactivating inward current was detected (Fig. 1A), similar to that mediated by endogenous ASIC1a channels in HEK 293 cells [29], confirming the ability of the epitope-tagged subunit to generate acid-sensing channels.
Of the four ENaC subunits, $\alpha, \beta, \gamma$ and $\delta$, we chose to work initially with $\alpha$-ENaC, because the $\alpha$ subunit forms functional homomeric channels, which $\beta$ - and $\gamma$-ENaC do not [30]. The $\delta$ subunit probably also forms functional homomeric channels [16], but little is known about its physiological role. tsA 201 cells were singly transfected with DNA encoding either HA/V5-tagged $\alpha$-ENaC or Myc-tagged ASIC1a, and protein expression was confirmed by immunofluorescence, using anti-V5, anti-HA and anti-Myc antibodies. As judged by the fluorescent staining pattern and comparison with the brightfield images, the tagged-subunits were localized predominantly in the endoplasmic reticulum, and
A

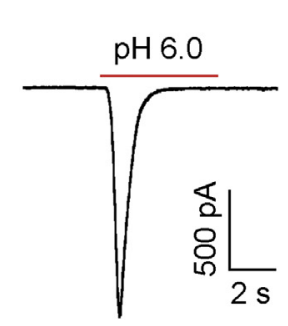

D

$\alpha-\mathrm{ENaC}$

(Anti-V5)

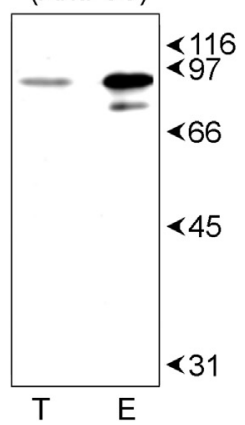

E

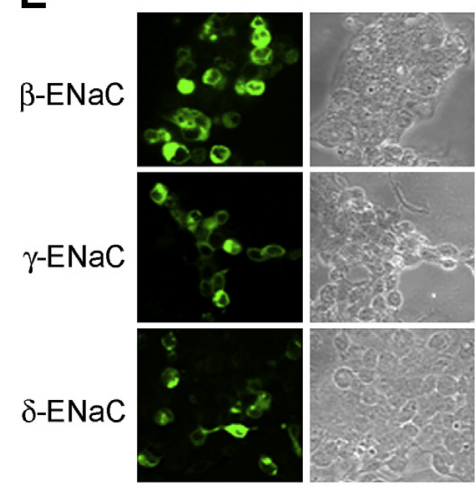

B $\alpha-\mathrm{ENaC}$ (Anti-V5)

$\alpha-\mathrm{ENaC}$

ASIC1a (Anti-Myc)
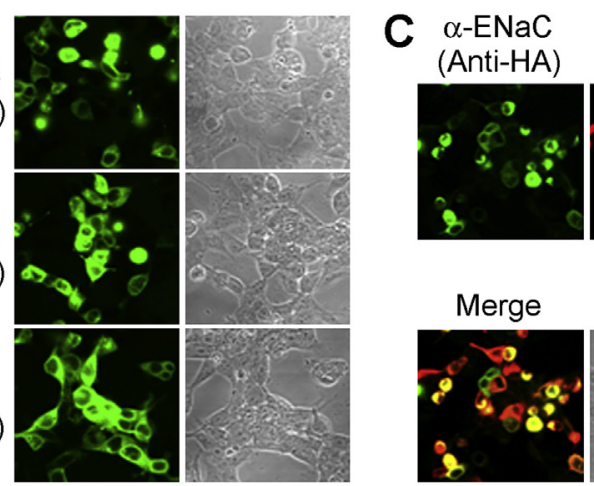

ASIC1a

(Anti-Myc)
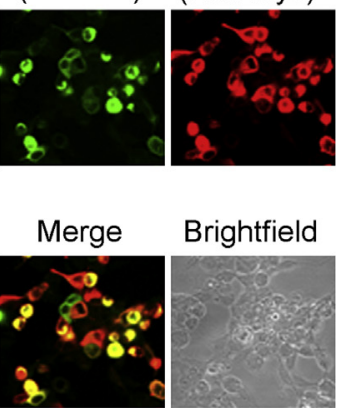

Brightfield

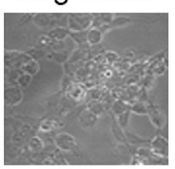

$\alpha-\mathrm{ENaC}$

(Anti-HA)

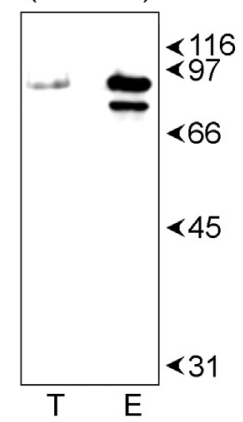

ASIC1a

(Anti-Myc)
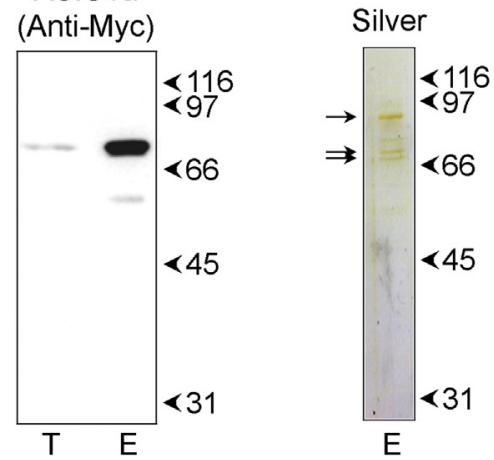

F

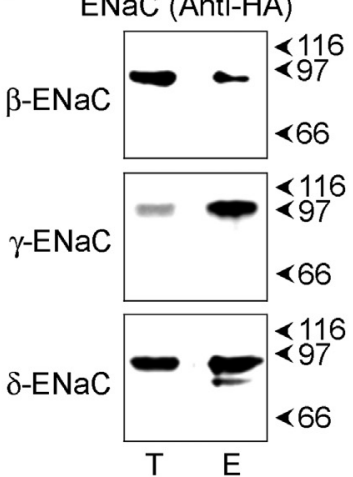

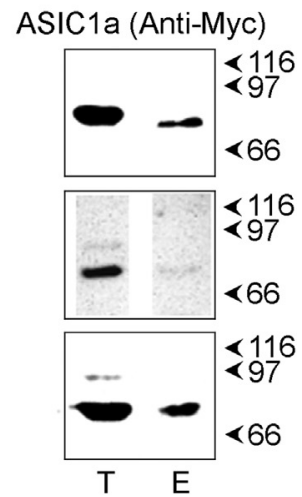

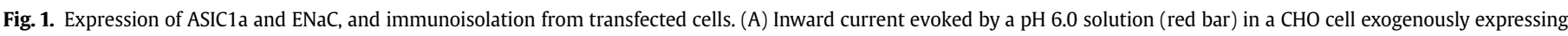

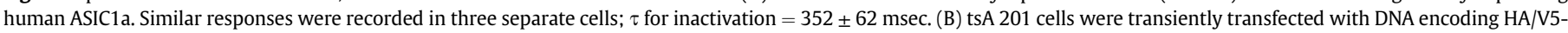

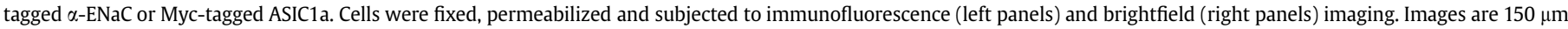

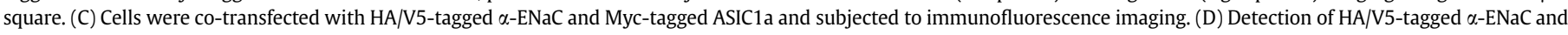

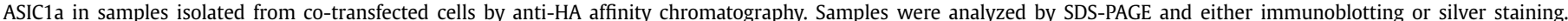

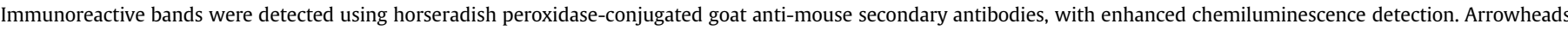

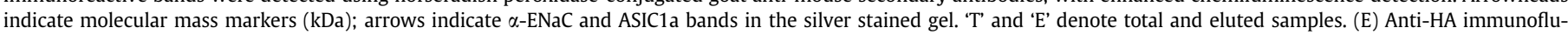

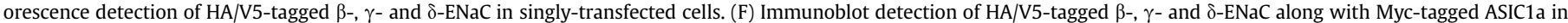

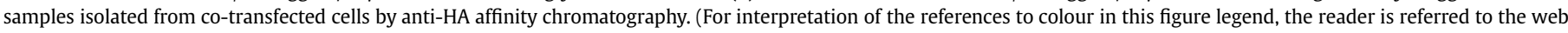
version of this article.) 
transfection efficiency was 50-60\% (Fig. 1B). When cells were cotransfected with DNA encoding $\alpha$-ENaC and ASIC1a, coexpression of the two proteins was seen in $40-50 \%$ of transfected cells (Fig. 1C). After double transfection, cells were solubilized in buffer containing $1 \%$ Triton $\mathrm{X}-100$ and proteins were isolated by anti-HA immunoaffinity chromatography. Total protein extracts and isolated proteins were immunoblotted. Major bands in the purified fractions were detected at $\sim 95 / 80 \mathrm{kDa}$ (anti-V5 and anti$\mathrm{HA}$ ) and $\sim 75 \mathrm{kDa}$ (anti-Myc), consistent with the expected sizes of tagged $\alpha$-ENaC [14] and ASIC1a, respectively (Fig. 1D). The same bands were seen on the corresponding silver-stained gel, indicating the purity of the sample. (Note that $\alpha$-ENaC and ASIC1a could also be co-isolated by anti-Myc immunoaffinity chromatography; data not shown). Densitometry of the bands on the anti-HA and antiMyc immunoblots revealed that $22 \pm 4(\mathrm{SEM}) \%(\mathrm{n}=3)$ of the total $\alpha$-ENaC and $11 \pm 5 \%(n=3)$ of the total ASIC1a appeared in the eluate, indicating a $47 \pm 12 \%$ co-isolation efficiency. This result is consistent with previous findings [21-23] that $\alpha$-ENaC and ASIC1a directly interact.

When cells were singly transfected with DNA encoding $\beta, \gamma$ and $\delta$ subunits, immunofluorescence images were similar to those seen with $\alpha$-ENaC (Fig. 1E). Co-isolation efficiencies of ASIC1a with the $\beta$, $\gamma$ and $\delta$ subunits were $24 \pm 9 \%, 2 \pm 2 \%$ and $22 \pm 10 \%$, respectively $(\mathrm{n}=3$ in all cases; Fig. 1F). Hence, of the four ENaC subunits, $\alpha$-ENaC has the strongest interaction with ASIC1a.

When the sample containing co-isolated ASIC1a and $\alpha$-ENaC was imaged by AFM, a heterogeneous distribution of particles was seen (Fig. 2A). To detect the presence of ASIC1a alongside $\alpha$-ENaC, we incubated the isolated proteins with anti-V5 antibodies (Abs) and anti-Myc Fab-fragments (Fabs). These two ligands are easily distinguishable by AFM based on their different sizes $\left(\sim 285 \mathrm{~nm}^{3}\right.$ and $\sim 95 \mathrm{~nm}^{3}$, respectively). Fig. 2B shows AFM images of the Ab/Fab- decorated particles. We saw particles that were either singly (Ab, arrowheads; Fab, arrows), doubly (asterisk) or triply decorated (\#) with Abs and/or Fabs. A gallery of individual particles singly decorated with Abs or Fabs is shown in Fig. 2C. A frequency distribution of volumes of all decorated particles, produced using Eq. (1), had three peaks, at $452 \pm 21 \mathrm{~nm}^{3}, 1013 \pm 113 \mathrm{~nm}^{3}$ and $1651 \pm 129 \mathrm{~nm}^{3}$ (Fig. 2D). The lowest peak (peak 1) closely corresponds to the size of a trimer containing ASIC1a and/or $\alpha$-ENaC subunits: according to Eq. (2), ASIC1a and $\alpha$-ENaC monomers should have molecular volumes of $142 \mathrm{~nm}^{3}$ and $180 \mathrm{~nm}^{3}$, respectively; a heteromeric ASIC1a/ $\alpha$-ENaC trimer would therefore have a molecular volume between $426 \mathrm{~nm}^{3}$ (ASIC1a trimer) and $540 \mathrm{~nm}^{3}$ ( $\alpha$-ENaC trimer). The larger volumes in the distribution are approximately twice (peak 2) and three times (peak 3 ) the size of a trimer, suggesting that the isolated proteins assemble not only as trimers but also as dimers and trimers of trimers, similar to $\alpha \beta \gamma$-ENaC [14].

A frequency distribution of volumes of doubly-decorated particles (Fig. 3A) had a major peak at $487 \pm 19 \mathrm{~nm}^{3}$, corresponding to the volume of an ASIC1a/ $\alpha$-ENaC trimer, and a minor peak at approximately double this volume, $1064 \pm 177 \mathrm{~nm}^{3}$, likely representing dimers of trimers. A volume range of $300-850 \mathrm{~nm}^{3}$ was set to identify trimer-sized particles. Among these particles, we found three types of double binding event: $\mathrm{Ab} / \mathrm{Fab}(\mathrm{n}=44), \mathrm{Ab} / \mathrm{Ab}$ $(\mathrm{n}=16)$ and Fab/Fab $(\mathrm{n}=31$; Table 1$)$. Seven triply-decorated particles were also seen: six Ab/Fab/Fab and one Ab/Ab/Fab. Galleries of doubly-decorated particles are shown in Fig. 3B-D. Crucially, Ab/Fab double binding events, which comprise about half of the total number of double decoration events, indicate the presence of trimer-sized particles containing both ASIC1a and $\alpha$ ENaC subunits.

To check that the double decoration events were genuine, we carried out three control experiments. As shown in Table 1, the
A

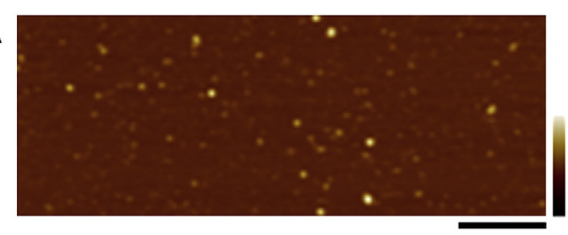

B

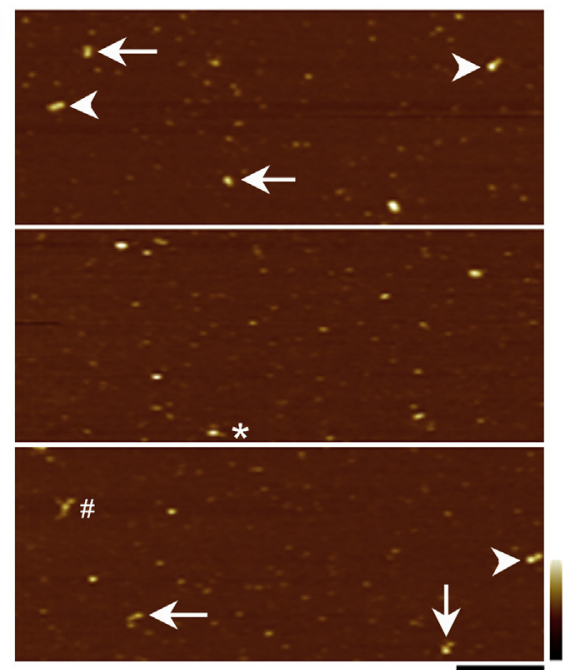

C
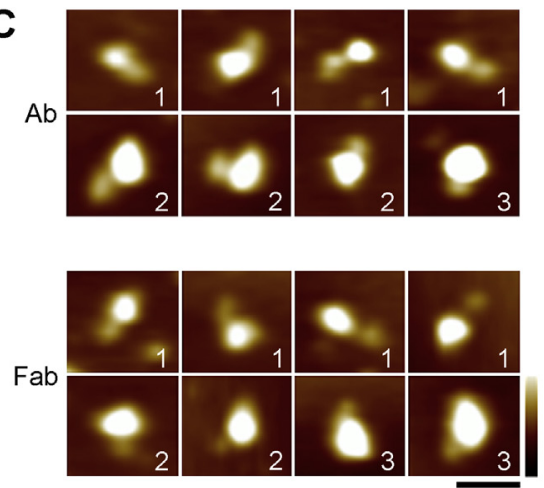

D

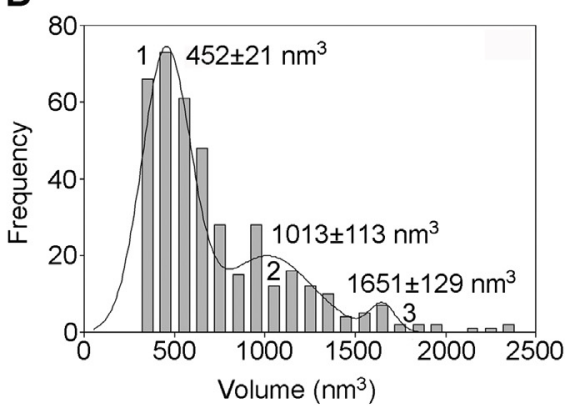

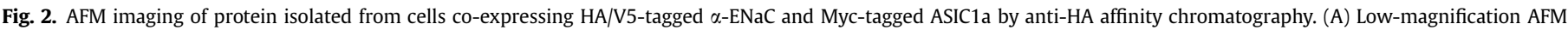

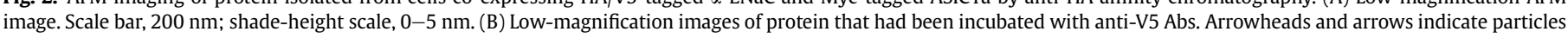

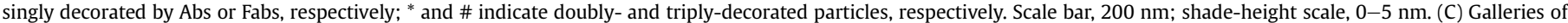

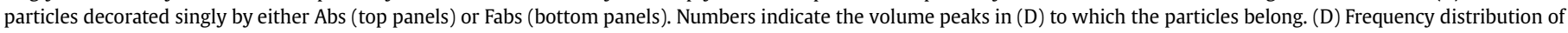
molecular volumes of all decorated particles. The curves indicate the fitted Gaussian functions. Peaks 1, 2 and 3, and the means of the distributions are indicated. 
A

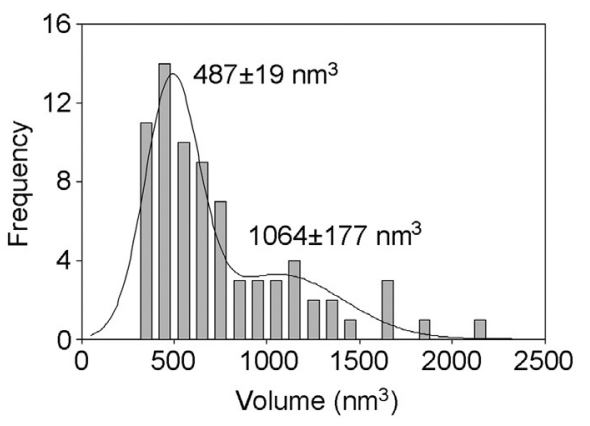

C
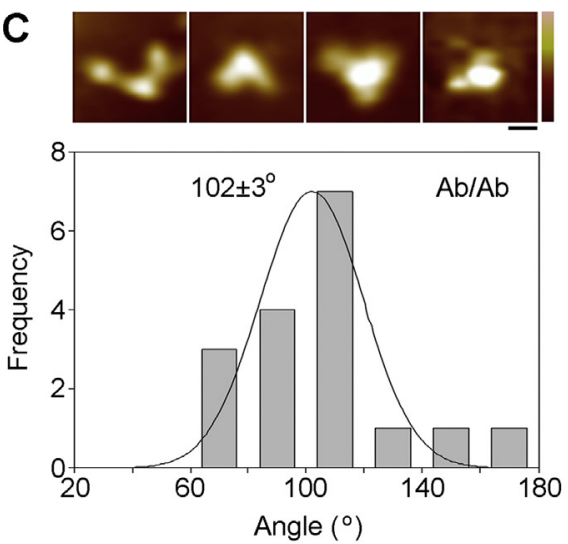

$\mathbf{E}$

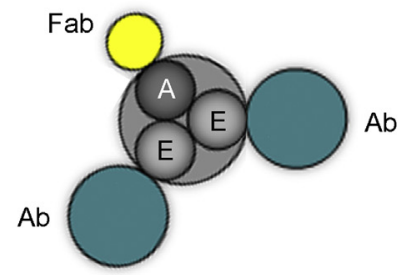

B
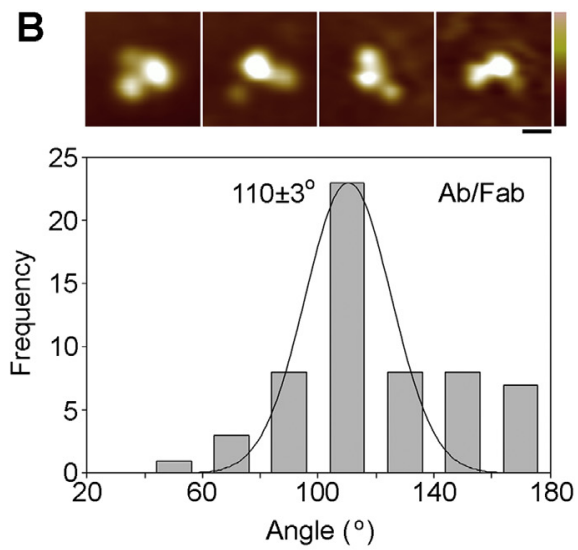

D
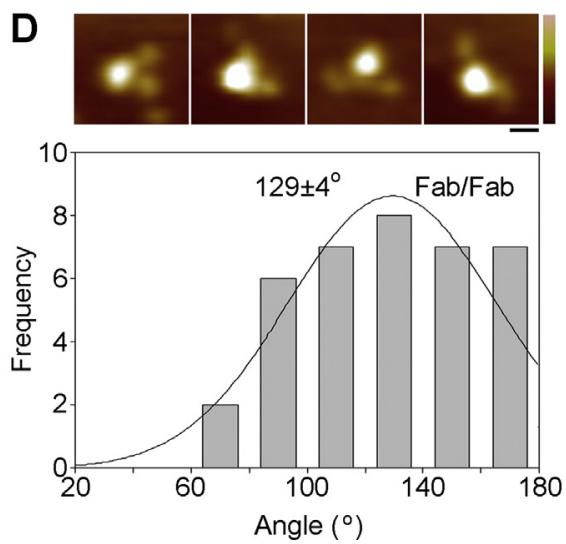

$1: 2$

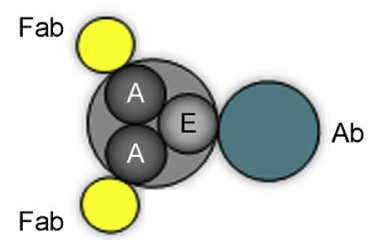

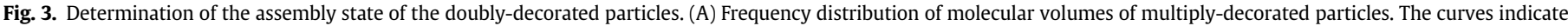

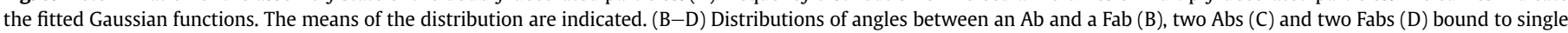

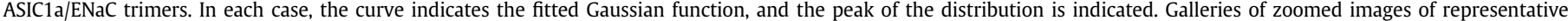

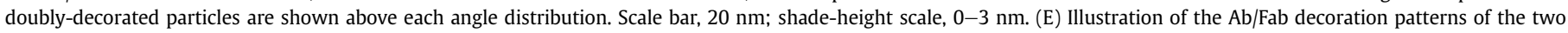
possible ASIC1a/ENaC heterotrimers.

frequency of double decoration events was reduced substantially when isolated protein was incubated with anti-FLAG Ab (control) plus anti-Myc Fab (positive), anti-V5 Ab (positive) plus anti-His Fab (control), or anti-FLAG Ab (control) plus anti-His Fab (control). Hence, the vast majority of double binding events observed with anti-V5 Ab plus anti-Myc Fab were specific.

A frequency distribution of angles between bound $\mathrm{Ab} / \mathrm{Fab}$ pairs had a single peak at $110 \pm 3^{\circ}(n=58$; Fig. $3 B)$, close to the angle of $120^{\circ}$ expected for a trimer. Similarly, the peak angle for $\mathrm{Ab} / \mathrm{Ab}$ pairs was $102 \pm 3^{\circ}(\mathrm{n}=17$; Fig. $3 \mathrm{C})$, and the peak angle for Fab/Fab pairs was $129 \pm 4^{\circ}(\mathrm{n}=37$; Fig. 3D). The frequency ratio of Fab/Fab and $\mathrm{Ab} / \mathrm{Ab}$ pairs is about $2: 1$, suggesting that the majority of ASIC $1 \mathrm{a} / \alpha$ ENaC channels are composed of two ASIC1a subunits and one $\alpha$ $\mathrm{ENaC}$ subunit. This deduction is supported by the findings that triple decoration with $\mathrm{Fab} / \mathrm{Fab} / \mathrm{Ab}$ and $\mathrm{Ab} / \mathrm{Ab} / \mathrm{Fab}$ occurred in a $6: 1$ ratio (above) and that Fab/Fab double binding events were

Table 1

Quantitation of complex formation.

\begin{tabular}{|c|c|c|c|c|}
\hline \multirow[t]{2}{*}{ Ab/Fab combination } & \multirow[t]{2}{*}{ Particles analyzed } & \multicolumn{3}{|c|}{ Double decoration events } \\
\hline & & $\mathrm{Fab} / \mathrm{Ab}$ & $\mathrm{Ab} / \mathrm{Ab}$ & $\mathrm{Fab} / \mathrm{Fab}$ \\
\hline Anti-V5 Ab + Anti-Myc Fab & 1744 & $44(2.5 \%)$ & $16(0.9 \%)$ & $31(1.8 \%)$ \\
\hline Anti-FLAG Ab + Anti-Myc Fab & 1454 & $4(0.3 \%)$ & $2(0.1 \%)$ & $17(1.2 \%)$ \\
\hline Anti-V5 Ab + Anti-His Fab & 1384 & $7(0.5 \%)$ & $4(0.3 \%)$ & $3(0.2 \%)$ \\
\hline Anti-FLAG + Anti-His Fab & 1561 & $5(0.3 \%)$ & $1(0.1 \%)$ & $0(0.0 \%)$ \\
\hline
\end{tabular}


relatively common $(\mathrm{n}=17)$ when particles were incubated with anti-FLAG Ab (control) plus anti-Myc Fab (positive; Table 1). Our conclusions about the subunit composition of the ASIC1a/ $\alpha-E N a C$ heterotrimer are summarized in the illustrations in Fig. 3E.

\section{Discussion}

Here we provide, for the first time, direct structural evidence for the formation of a cross-clade heterotrimeric ion channel from ASIC and $\mathrm{ENaC}$ subunits. This finding raises the possibility that various cross-clade ASIC/ENaC channels exist, which display either a combination of the individual properties of the two channels or entirely novel features. The existence of a novel amiloride-sensitive current in glioblastomas, but not in non-cancerous astrocytes, has been mentioned above [7]. ASICs and ENaCs have individually been associated with cell migration and proliferation [9,10,31]; however, our finding suggests a potential involvement of ASIC1a/ENaC heteromeric channels in these processes.

ASIC/ENaC heteromers might also function as mechanosensors. A mechanosensitive role for $\mathrm{ENaC}$ has been proposed in vascular smooth muscle cells (VSMCs) [32], in which only the $\beta$ and $\gamma$ subunits are expressed. The lack of the conducting $\alpha$ subunit makes it unlikely that ENaC in VSMCs has the same classic function as in the kidney. Inhibition or knockdown of $\mathrm{ENaC}$ in VSMCs, as well as knockdown of ASIC, which is equally expressed in these cells, resulted in a blockade of myogenic constriction [33-35]. These findings are consistent with the existence of a functional ASIC/ENaC channel. (Note that both $\beta$ - and $\gamma$-ENaC could be co-isolated with ASIC1a in our study, albeit less efficiently than $\alpha$-ENaC). Further evidence indicates that an ASIC/ENaC heteromer may be responsible for mechanosensitivity in mammalian muscle spindles [36]. ASIC and ENaC are also co-expressed in a variety of other tissues and cell types, including gliomas, glioblastomas and astrocytes $[7,22,23]$. We suggest that cross-clade channels are formed in many cell types and that they participate in processes such as sensory perception, and pathological conditions such as cystic fibrosis, hypertension and pain. These diseases have so far only been associated with either one of the ion channels (reviewed in Ref. [37]), and consequently drug development has involved targeting of the individual channels. Although complete characterization of channel functionality and regulation is still needed, the existence of ASIC/ $\mathrm{ENaC}$ heteromers increases the repertoire of available phenotypes and may provide novel therapeutic targets.

\section{Acknowledgments}

J.M.E. and P.J. are supported by Kidney Research U.K. A.P.S. was a member of the University of Cambridge $\mathrm{MB} / \mathrm{PhD}$ Programme, and was supported by the Jean Shanks Foundation and the James Baird Fund. A research stay of S.H. at Cambridge was supported by a $\mathrm{PhD}$ fellowship from the Bayerische Forschungsstiftung.

\section{Transparency document}

Transparency document related to this article can be found online at http://dx.doi.org/10.1016/j.bbrc.2015.05.091.

\section{References}

[1] S. Kellenberger, L. Schild, International union of basic and clinical pharmacology. XCI. structure, function, and pharmacology of acid-sensing ion channels and the epithelial $\mathrm{Na}^{+}$channel, Pharmacol. Rev. 67 (2015) 1-35.

[2] J. Jasti, H. Furukawa, E.B. Gonzales, E. Gouaux, Structure of acid-sensing ion channel 1 at $1.9 \AA ̊$ resolution and low pH, Nature 449 (2007) 316-323.

[3] M.P. Price, S.L. Mcllwrath, J. Xie, C. Cheng, J. Qiao, D.E. Tarr, K.A. Sluka T.J. Brennan, G.R. Lewin, M.J. Welsh, The DRASIC cation channel contributes to the detection of cutaneous touch and acid stimuli in mice, Neuron 32 (2001) 1071-1083.

[4] N. Voilley, J. de Weille, J. Mamet, M. Lazdunski, Nonsteroid antiinflammatory drugs inhibit both the activity and the inflammation-induced expression of acid-sensing ion channels in nociceptors, J. Neurosci. 21 (2001) 8026-8033.

[5] J.A. Wemmie, J. Chen, C.C. Askwith, A.M. Hruska-Hageman, M.P. Price, B.C. Nolan, P.G. Yoder, E. Lamani, T. Hoshi, J.H. Freeman Jr., M.J. Welsh, The acid-activated ion channel ASIC contributes to synaptic plasticity, learning, and memory, Neuron 34 (2002) 463-477.

[6] Z.G. Xiong, G. Pignataro, M. Li, S.Y. Chang, R.P. Simon, Acid-sensing ion channels (ASICs) as pharmacological targets for neurodegenerative diseases, Curr. Opin. Pharmacol. 8 (2008) 25-32.

[7] B.K. Berdiev, J. Xia, L.A. McLean, J.M. Markert, G.Y. Gillespie, T.B. Mapstone, A.P. Naren, B. Jovov, J.K. Bubien, H.L. Ji, C.M. Fuller, K.L. Kirk, D.J. Benos, Acidsensing ion channels in malignant gliomas, J. Biol. Chem. 278 (2003) 15023-15034.

[8] X. Dong, K.H. Ko, J. Chow, B. Tuo, K.E. Barrett, H. Dong, Expression of acidsensing ion channels in intestinal epithelial cells and their role in the regulation of duodenal mucosal bicarbonate secretion, Acta Physiol. 201 (2011) 97-107.

[9] S.C. Grifoni, K.P. Gannon, D.E. Stec, H.A. Drummond, ENaC proteins contribute to VSMC migration, Am. J. Physiol. Heart Circ. Physiol. 291 (2006) H3076-H3086.

[10] S.C. Grifoni, N.L. Jernigan, G. Hamilton, H.A. Drummond, ASIC proteins regulate smooth muscle cell migration, Microvasc. Res. 75 (2008) 202-210.

[11] C.J. Benson, J. Xie, J.A. Wemmie, M.P. Price, J.M. Henss, M.J. Welsh, P.M. Snyder, Heteromultimers of DEG/ENaC subunits form $\mathrm{H}^{+}$-gated channels in mouse sensory neurons, Proc. Natl. Acad. Sci. U. S. A. 99 (2002) 2338-2343.

[12] M. Hesselager, D.B. Timmermann, P.K. Ahring, pH dependency and desensitization kinetics of heterologously expressed combinations of acid-sensing ion channel subunits, J. Biol. Chem. 279 (2004) 11006-11015.

[13] R. Waldmann, G. Champigny, F. Bassilana, C. Heurteaux, M. Lazdunski, A proton-gated cation channel involved in acid-sensing, Nature 386 (1997) $173-177$.

[14] A.P. Stewart, S. Haerteis, A. Diakov, C. Korbmacher, J.M. Edwardson, Atomic force microscopy reveals the architecture of the epithelial sodium channel (ENaC), J. Biol. Chem. 286 (2011) 31944-31952.

[15] D.J. Benos, B.A. Stanton, Functional domains within the degenerin/epithelial sodium channel (Deg/ENaC) superfamily of ion channels, J. Physiol. 520 (1999) 631-644.

[16] S. Haerteis, B. Krueger, C. Korbmacher, R. Rauh, The $\delta$-subunit of the epithelial sodium channel (ENaC) enhances channel activity and alters proteolytic ENaC activation, J. Biol. Chem. 284 (2009) 29024-29040.

[17] T. Giraldez, P. Rojas, J. Jou, C. Flores, D. Alvarez de la Rosa, The epithelial sodium channel $\delta$-subunit: new notes for an old song, Am. J. Physiol. Ren. Physiol. 303 (2012) F328-F338.

[18] S. Matalon, A. Lazrak, L. Jain, D.C. Eaton, Invited review: biophysical properties of sodium channels in lung alveolar epithelial cells, J. Appl. Physiol. 93 (2002) 1852-1859.

[19] P.M. Snyder, The epithelial $\mathrm{Na}^{+}$channel: cell surface insertion and retrieval in $\mathrm{Na}^{+}$homeostasis and hypertension, Endocr. Rev. 23 (2002) 258-275.

[20] B.K. Berdiev, Y.J. Qadri, D.J. Benos, Assessment of the CFTR and ENaC association, Mol. Biosyst. 5 (2009) 123-127.

[21] R.H. Meltzer, N. Kapoor, Y.J. Qadri, S.J. Anderson, C.M. Fuller, D.J. Benos, Heteromeric assembly of acid-sensitive ion channel and epithelial sodium channel subunits, J. Biol. Chem. 282 (2007) 25548-25559.

[22] N. Kapoor, R. Bartoszewski, Y.J. Qadri, Z. Bebok, J.K. Bubien, C.M. Fuller, D.J. Benos, Knockdown of ASIC1 and epithelial sodium channel subunits inhibits glioblastoma whole cell current and cell migration, J. Biol. Chem. 284 (2009) 24526-24541.

[23] N. Kapoor, W. Lee, E. Clark, R. Bartoszewski, C.M. McNicholas, C.B. Latham, Z. Bebok, V. Parpura, C.M. Fuller, C.A. Palmer, D.J. Benos, Interaction of ASIC1 and ENaC subunits in human glioma cells and rat astrocytes, Am. J. Physiol. Cell Physiol. 300 (2011) C1246-C1259.

[24] T.W. Sherwood, K.G. Lee, M.G. Gormley, C.C. Askwith, Heteromeric acidsensing ion channels (ASICs) composed of ASIC2b and ASIC1a display novel channel properties and contribute to acidosis-induced neuronal death, J. Neurosci. 31 (2011) 9723-9734.

[25] J.K. Bubien, H.L. Ji, G.Y. Gillespie, C.M. Fuller, J.M. Markert, T.B. Mapstone, D.J. Benos, Cation selectivity and inhibition of malignant glioma $\mathrm{Na}^{+}$channels by Psalmotoxin 1, Am. J. Physiol. Cell Physiol. 287 (2004) C1282-C1291.

[26] S.W. Schneider, J. Lärmer, R.M. Henderson, H. Oberleithner, Molecular weights of individual proteins correlate with molecular volumes measured by atomic force microscopy, Pflügers Arch. 435 (1998) 362-367.

[27] D.W. Scott, Optimal and data-based histograms, Biometrika 66 (1979) 605-610.

[28] B. Welch, The generalisation of student's problems when several different populaion variances are involved, Biometrika 24 (1947) 28-35.

[29] M.J. Gunthorpe, G.D. Smith, J.B. Davis, A.D. Randall, Characterisation of a human acid-sensing ion channel endogenously expressed in HEK293 cells, Pflügers Arch. 442 (2001) 668-674.

[30] C.M. Canessa, L. Schild, G. Buell, B. Thorens, I. Gautschi, J.D. Horisberger, B.C. Rossier, Amiloride-sensitive epithelial $\mathrm{Na}^{+}$channel is made of three homologous subunits, Nature 367 (1994) 463-467. 
[31] M. Bondarava, T. Li, E. Endl, F. Wehner, $\alpha$-ENaC is a functional element of the hypertonicity-induced cation channel in HepG2 cells and it mediates proliferation, Pflügers Arch. 458 (2009) 675-687.

[32] H.A. Drummond, S.C. Grifoni, N.L. Jernigan, A new trick for an old dogma: ENaC proteins as mechanotransducers in vascular smooth muscle, Physiology 23 (2008) 23-31.

[33] N.L. Jernigan, H.A. Drummond, Myogenic vasoconstriction in mouse renal interlobar arteries: role of endogenous $\beta$ and $\gamma \mathrm{ENaC}$, Am. J. Physiol. Ren. Physiol. 291 (2006) F1184-F1191.

[34] K.P. Gannon, L.G. Vanlandingham, N.L. Jernigan, S.C. Grifoni, G. Hamilton, H.A. Drummond, Impaired pressure-induced constriction in mouse middle cerebral arteries of ASIC2 knockout mice, Am. J. Physiol. Heart Circ. Physiol 294 (2008) H1793-H1803.

[35] Z. Guan, J.S. Pollock, A.K. Cook, J.L. Hobbs, E.W. Inscho, Effect of epithelia sodium channel blockade on the myogenic response of rat juxtamedullary afferent arterioles, Hypertension 54 (2009) 1062-1069.

[36] A. Simon, F. Shenton, I. Hunter, R.W. Banks, G.S. Bewick, Amiloride-sensitive channels are a major contributor to mechanotransduction in mammalian muscle spindles, J. Physiol. 588 (2010) 171-185.

[37] Y.J. Qadri, A.K. Rooj, C.M. Fuller, ENaCs and ASICs as therapeutic targets, Am. J. Physiol. Cell Physiol. 302 (2012) C943-C965. 